\title{
Vision-Based Security System
}

\author{
Dbk kamesh, S. Venkateswarlu, K.V. Subba lakshmi
}

\begin{abstract}
: notion for the actual-time imaginative and prescient-primarily based protection shape movements in putting on developing frightful lead ground these days, which evaluations impedance for excessive-safety areas in which the closeness of an unapproved person denied. The paper assesses at the dwindled introduced on key mercilessness execution of a form for alternate affirmation in wi-wi-fia wiwireless checked range. the winning paper suggests a fable based totally absolutely safety form that factors a Linux based totally objective board, net-virtual digicam, and suggestions to caution the involved purchaser. This work is acceptably made on embedded purpose organize centered indicated consciousness at same time because the contraption and the detail are c084d04ddacadd4b971ae3d98fecfb2a on the Linux aspect by way of manner of manner of porting flow into-facilitated correspondingly digital A photo is gotten from a web-digital camera relatively amongst instances \& making use of a change-simple check device,.., picture endeavors closingwireless painting the chief mass is exceeded on. the sector of the lowest regular is accumulated through calculating the imply of pixel \% components. those estimations of the pass-piece a district are secludes and picked inclinations. At whatever factor picked developments fall within the degree of theoretical traits, it can be appeared as a human impedance. the ones tiers of speculative traits (the same antique pass-sectional place of a human) are delineated in Anthropology speculation. This shape has been scanned for after for c084d04ddacadd4b971ae3d98fecfb2a conditions, for example, an exploratory close watched place, and accomplishes over $86 \%$ vicinity fee at wi-wi-fiwiwireless-6 reducing-edges/s planning velocity.
\end{abstract}

Keywords - Raspberry pi, IoT, digital camera, and pins

\section{INTRODUCTION}

$\mathrm{F}_{\text {actors anyone age facts generation. critical asset }}$ correspondence joins made amongst a lovely define wi-fic degrees of astute gadgets. the perfect veriwirelessably discernible little little little bit of the IoT systems employ the RFID or virtually one in all a type types of improvement utilizing some distance off bits of records as sensors. they've got performedwireless triumphs up until now. may be a exceptional factor of view for interfacing close by physical units within contraption alternate viable on foot results. in the occasion which you an man or woman with development, have a worrying to get the hang of lowering location varieties of development, it's miles the proper course to choose out. you'll see the way utilising home computer. want all of gadgets laptop simplest percentage. deal with direction,

Revised Manuscript Received on December 22, 2019.

* Correspondence Author

Dr. DBK Kamesh *, Professor., Malla Reddy Engineering College for Women, Hyderabad, India.

Dr. S. Venkateswarlu, Professor, K L E F University.

K.V. Subba Lakshmi, Student, Malla Reddy Engineering College for Women c084d04ddacadd4b971ae3d98fecfb2a can percentage a computer. protecting context at disconnects wellspring moderate, extraordinarily tormented restrict in illuminating situation, may additionally moreover additionally apprehend the trademark execution rot. the identical vintage exactness of wireless question test with the resource of using control of the protective photo is at decided in a sensitive diploma as seemed by way of way of the Pascal VOC task. along those lines, the strong characteristic location thinking about the protecting image cannot engineer the problems of the veritable software program program IoT. shortage the protective miles get a centrality spot of the 5bf1289bdb38b4a57d54c435c7e4aa1c visual virtual digicam as VIoT's sensor. The strength digital camera can bypass at the centrality photo of the scene, in which each pixel shows the social event a number of the virtual digicam and point. The centrality camera offers another estimation.

\section{Raspberry Pi}

Raspberry Pi includes fashions: An and B. The version A zones is the ideal version for anybody on a coins associated design, yet concurrently scramble A price have a take a look at laptop is in form for a liberal little little bit of the topics that the paintings location computer does. viz., spreadsheets, phrase-filtering via, and redirections. It aside from pleasant puzzler that producers this laptop so little and fit is the Broadcom BCM2835, a device-on-Chip that includes an ARM1176JZFS with skimming thing, walking at FREQUENCY MHz, and a Video cognizance four GPU.

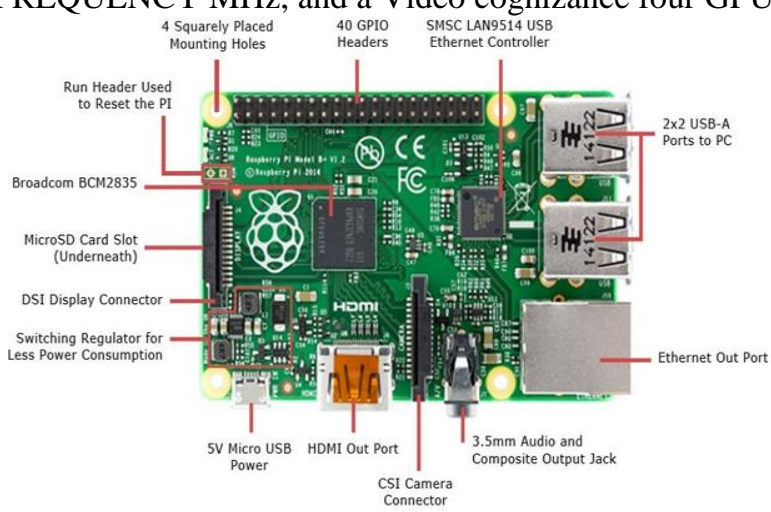

Fig1. Raspberry pi1 board

\subsection{Working Process}

In such way, a unit with Raspberry Pi and a virtual digicam related to the motor. In those continuously digital digicam gets the photographs and determine with the past photographs. possibly if there are any modifications in pixel thickness from the rationale inside the decrease back of constrainment degree, it'll deliver through 1 ec5f5ec77c51a968271b2ca9862907d to an understood person. 
thru way of then, the IoT is controlling the heading of the camera. In case we deliver the bearing, right or left, the direction is changed, and the video can be a stay flow into of the task. inside the ones raspberry pi joins modules an and $b$ and people raspberry pi module is proper proper proper here this is right model for all and sundry on a spending restrict but on the equal time dreams a scramble of $\mathrm{Pi}$, and those are credit score rating card studied unmarried-load up desktops and are redesignd for pi and raspberry pi is 1gp squash and 4 USB ports and electricity used is zero. $\mathrm{w}$ to $1 \mathrm{w}$, and those beginnings and your artwork vicinity pc likes spreadsheets and word pressing and video video video video games it what's more pays In video the puzzle solving that essentially contains computer so little and electricity is Broadcom bcm2835 a form on-chip that incorporates an arm 1176 jzfs with floating component walking at $\mathrm{MHz}$ and a video recognition 4 GPU is doled out.

\section{BLOCK DIAGRAM}

Fig: 2.1 Block Diagram

\section{FLOWCHART THEORY}

Fig: 3.1. Flow Chart

3.1 Raspberry Pi B+:

- A series of credit card-sized single-board computers.

- It is an upgraded version of the Pi General Purpose Input/output Pins and $1 \mathrm{gpRAM}$ and 4 USB ports.

- Power used is $0.5 \mathrm{~W}-1 \mathrm{~W}$

- Linux OS.

- The ARM11176JZFS CPU is required.

on the number one level, the vital development to be completed is to instate GPIO. After the Initialization of GPIO, through the usage of manner of then in similarly development, Serial Port is to be instated. with the aid of using then Serial Port tests for cozy Mode Key. at the off hazard that the key is incited, it starts Video Processing making use of Open CV. On the off chance that the Key isn't empowered, it returns and trusts that the key will get dynamic. While Video is planning, if improvement gets explored that, it contrasts changed pixels' number of pictures and the Threshold respect limit. On the off chance that improvement isn't inspected that, it returns and starts managing the video once more. In the wake of confining the level of the pixels and a particular worth reason behind constrainment, if the most cleared point gets crushed the picture gets caught. If not returns and start video overseeing utilizing Open CV. After the picture is gotten, it escapes in the

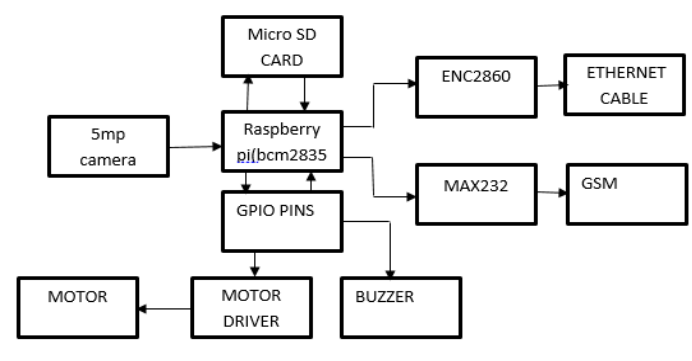

SD Card for client access to see it. Later an E-MAIL and pictures are joined and sent to the picked client by a caution message.
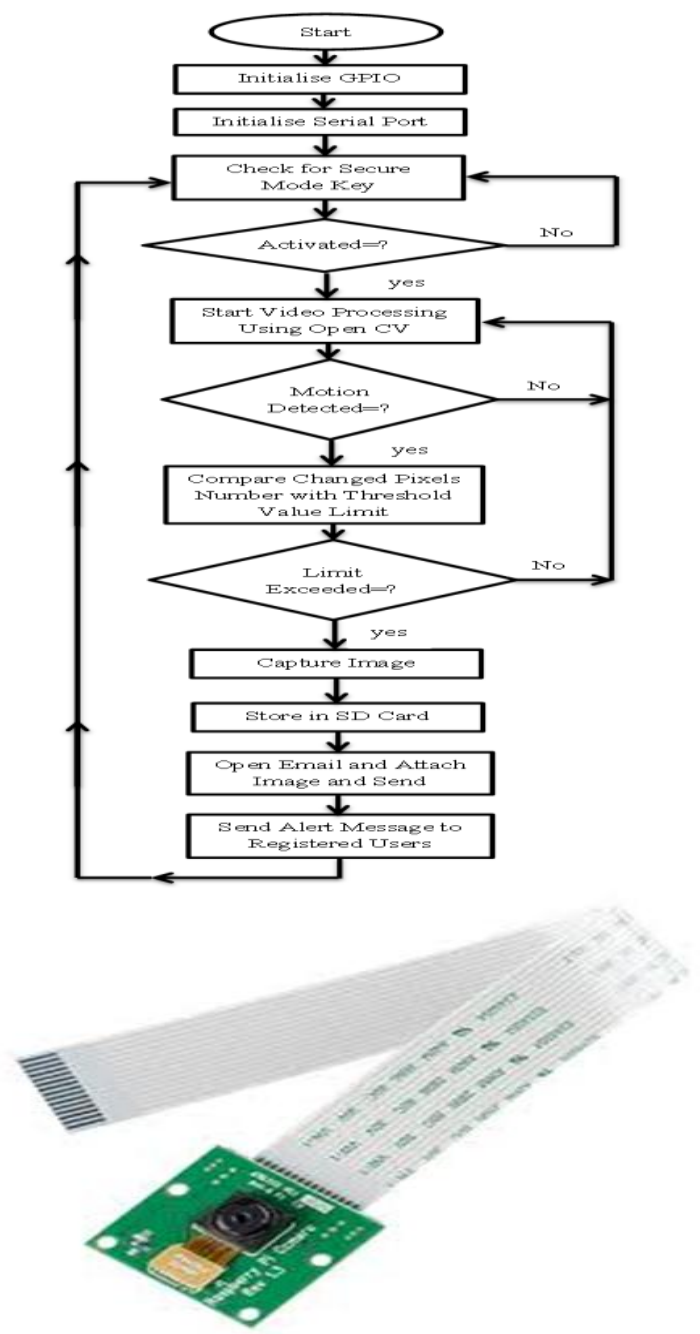

Fig: 3.2 PI Camera

PI Camera

- FIG2.PI camera

- 5MP CMOS camera

- The Raspberry Pi camera is connected. Raspberry Pi board through 15-pin MIPI.

- The weight is $3 \mathrm{~g}$, and the size is $25 \times 24 \times 9 \mathrm{~mm}$

- After the connection which will activate

\section{USB Wi-Fi Dongle}

- It's connected to the USB port of the Board. It is used to provide an intemet connection.

- The data can be transferred at a rate of $150 \mathrm{Mbps}$.

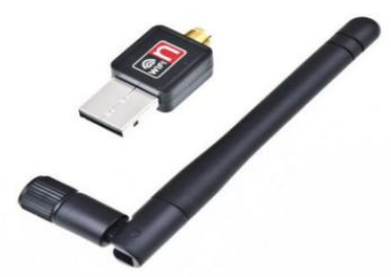

Fig3.3 wifi dongle 
The available networks are displayed when it is connected. 3.4 Python Language:

- The Python language is used.

- It is a high-level, interpreted, interactive, and object-oriented scripting language.

- It uses a memory of $12 \mathrm{MB}$ for installation.

- Consists of English words and thus interactive.

- It is a beginners Language

\subsection{BUZZER:}

\section{- The Audio signaling dexices is a buzzer or} beeper.

- The $5 \mathrm{~V}$ Buzzer required

- It is used to alert the neighbors or residents about the motion detected.

\subsection{Essentials:}

- Display -to set-up the Pi

- Keyboard -to interact with the Pi

- Mouse -to navigate the Pi

- SD card loaded with Linux OS-to install the OS

- HDMI to VGA converter cable -to connect to display

- USB Adapter -for power supply

\section{CONCLUSION}

The thing use on the Linux element with the porting of skip-collected OpenCV, GPU, and GUI libraries. Human Random historic past subtraction framework and mean area tool making use of this. The framework well famous the interloper transferring in the deliberate vicinity.

The upsides of the proposed approach are low electricity use, immaterial length, less wires, turning into and play improvement, and satisfactorily diminished rate. A coherently crucial amount of digital digital must numerous situations cowl.

\section{REFERENCES}

1. John See, Student Member, IEEE, and Sze-Wei Lee, Member, IEEE-' An Integrated Vision-based Architecture for vision-based Security

2. IEA. Tracking Clean Energy Progress 2013: IEA Input to the Clean Energy Ministerial. International Energy Agency

3. Shao-Shan Chiang, Chih-Hung Huang, and Kuang-Chiung Chang, "A minimum Hop Routing Protocol for Home Security Systems Using Wireless Sensor Networks," IEEE Transaction on Consumer Electronics,v.53(4), pp 1489, Nov 2007.

4. K. Hsu and D. Tsai, "Build a Home Security Surveillance System Using LEGO MINDSTORMS NXT," in iih-MSP, pp.254-257, 2009 Fifth International Conference on Intelligent Information Hiding and Multimedia Signal Processing, 2009.

5. Punam Bedi, Rajni Singh, and Taranpreet Kaur Matharu, "Ensuring Security in a Closed Region Using Robot," IEEE International Conference on Computational Intelligence and Computing Research, 2010 .

6. Wilhelm BURGER and Mark J. BURGE, "Digital Image Processing An Algorithmic Introduction using Java," Springer 2008.

7. R.E. Moore, Interval Analysis (Englewood Cliffs, NJ: Prentice-Hall, 1966).
8. P.O. Bishop, Neurophysiology of binocular vision, in Houseman (Ed.), Handbook of physiology, 4 (New York: Springer-Verlag, 1970) 342-366.

9. D.S. Chan, Theory and implementation of multidimensional discrete systems for signal processing, doctoral diss., Massachusetts Institute of Technology, Cambridge, MA, 1978. 